\title{
Tabasco:
}

\section{una bibliografía comentada}

\author{
Ma. Eugenia Arias, Ana Lau, Ximena Sepúlveda
}

\begin{abstract}
El pasado está (...) constituido, en una primera aprehensión, por (una) masa de hechos menudos, los unos resplandecientes, los otros oscuros e indefinidamente repetidos...
\end{abstract}

Fernand Braudel

Cuando nos abocamos al estudio de Tabasco para realizar, en primera instancia, una antologia de textos históricos, iniciamos la búsqueda en las principales bibliotecas de la ciudad de México y del estado y procedimos a recopilar los materiales escritos que se adecuaban más a nuestro propósito.

La consulta de los catálogos nos alentó, pues además de las obras generales que consideraban la historia de la entidad únicamente en su relación con los momentos relevantes del acontecer político nacional, encontramos un buen número de textos, tanto globales como específicos que nos permitieron adentrarnos en el estudio, asi como realizar la antologia ya mencionada.

La lejanía del centro administrativo de la República, la conformación geográfica y la falta de comunicaciones habian relegado al olvido al estado, como consecuencia, esto repercutió en cierta manera en su historiografía, la cual adquiere sus ritmos y tiempos propios, que no siempre responden a los sucesos nacionales.

Consecuencia lógica del trabajo de selección de textos fue la lectura de toda la bibliografia que encontramos disponible y que trataba el periodo que va desde la conformación del Estado nacional en 1824 hasta la renovación del pacto federal, luego de la Revolución mexicana, en 1919. La presencia o ausencia de estudios sobre determinadas épocas o momentos históricos es significativa, tiene causas humanas que el historiador no puede pasar por alto por lo que habría que recurrir a los archivos.

Una de las tareas más tediosas para un investigador, es localizar los materiales necesarios para realizar su trabajo. Con objeto de facilitar la tarea ofrecemos aquí una bibliografía comentada con 64 obras, que puede servir de guía al lector, indicándole su localización y, además, el contenido de la obra en un breve resumen.

Factores comunes o particulares de los textos permiten hacer una valoración historiográfica: concepción del momento que relatan, carencia o riqueza de una aportación, conciencia histórica de quienes escriben, autenticidad de la fuente, etc. La tendencia historiográfica es generalmente la propia del siglo XIX. Salvo algunas excepciones, lo que nos ofrecen los autores son historias episódicas, de acontecimientos o hechos menudos; del qué sucedió y no siempre del por qué; no hay una visión integral de un proceso más amplio. Encontramos un marcado én- 
fasis en el aspecto político, a veces en lo geográfico y militar, escaso en lo socioeconómico.

Este último aspecto no carece de fuentes; existen, pero no han sido analizadas; se encuentran básicamente en la hemerografía de la época, que poco se ha estudiado.

Fuentes primarias y secundarias, tales como colecciones de documentos y hemerografía, testimonios de los actores del drama histórico, crónicas, relatos de viajeros, novela con trasfondo histórico, constituyen los títulos seleccionados.

En su mayoría, los autores son tabasqueños; sin embargo, hemos incluido también a escritores de otros estados de la República y a extranjeros (el barón de Waldeck y Robert West). Son pocos los trabajos realizados en los últimos veinte años que hablan de la época que tratamos.

Los libros que comentamos a continuación pueden ser clasificados, grosso modo, de la siguiente manera:

- Historias generales: entre ellas cabe mencionar el Compendio... de Gil y Sáenz, primer resumen de historia tabasqueña, fuente que sirve de apoyo a muchos autores para sus estudios.

- Compilaciones: reúnen documentos y hemerografía de la época. Gracias a la labor de rescate de autores como Manuel Mestre Ghigliazza y Francisco J. Santamaría, nos llegan escritos cuyos originales han desaparecido.

- Monografías: investigaciones específicas sobre temas de indole diversa, que tocan desde cuestiones económicas, pasando por historias de pueblos y ciudades, hasta estudios sobre el desarrollo de la gesta revolucionaria en el estado.

- Testimonios: hacen referencia a las experiencias vividas por los: autores. En su mayoría recrean el acontecer diario, relatan los hechos menudos, la vida cotidiana, lo que no entra en los hechos heróicos e importantes; nos permiten conocer al hombre en su, medio. Como ejemplo, podemos mencionar la obra de Andrés Iduarte.

- Informes y estadísticas: necesarias para conocer el aspecto económico que privaba en el estado, a fin de conformar una visión integral de la historia. Contienen datos de diversas épocas y asuntos, lo que nos permite la comparación.

- Novelas: sustentados en algún hecho histórico, los literatos crean personajes ficticios que se mueven en ese trasfondo y nos proporcionan información de asuntos tales como la Intervención francesa o la Revolución.

Considerando que algunas de las obras reseñadas entran en más de uno de los apartados mencionados, hemos decidido presentarlas en orden alfabético.

Los interesados en conocer la historia de Tabasco y los investigadores encontrarán en esta bibliografia materia prima para trabajar y, complementándola con la consulta de archivos, podrán hallar las características y ritmos particulares en ese devenir local. 
BIM

972.63

AGU.t.

Aguila Figueroa, Bernardo Del, Tabasco (En la geografia i en la historia), México, Consejo Editorial del Gobierno del Estado de Tabasco, 1980, 238 p.

Sumario de la geografía y la historia tabasqueñas, narrado con esmero, este trabajo se apoya en fuentes primarias, secundarias y copiosa hemerografía.

La parte geográfica ofrece un documentado panorama de aspectos tales como la descripción del estado, sus límites, regiones, constitución geológica, orográfica, botánica e hidrológica, en el que el autor abunda en hallazgos y argumentaciones de los científicos tabasqueños más representativos.

En cuanto a la sección histórica, relata el acontecer tabasqueño desde el periodo prehispánico hasta 1946. La narración, precisa y cronológica, contiene algunas interpretaciones que permiten al lector penetrar en el complejo vericueto de la historia del estado.

BNAL

972.62.092.5

AGU.r

Aguirre Colorado, Rafael, Revolución constitucionalista en el estado de Tabasco, s.l., Talleres Gráficos del Sudeste, 1934, 50 p.

Se trata de un folleto en que el autor relata su ac-

INAH

FTS

2329 tuación durante 1913: su incorporación a la lucha contra Huerta en el estado de Tabasco y sus contactos tanto con los hombres que se habian levantado en armas como con el gobernador huertista, hasta su salida del estado a fines del año. Señala la importancia de que los actores de ciertos hechos los den a conocer, puesto que así quienes escriban la historia tendrán mayor información a la hora de redactar sus estudios.

El texto tiene notas a pie de página que dan detalles sobre los acontecimientos en los que el autor intervino directamente. Pese a sus propósitos, se refiere a un tiempo tan breve y a un grupo tan pequeño que casi no proporciona información general sobre lo que sucedía en el estado. La obra carece de bibliografía.

BIM.

Arias G., Ma. Eugenia, Ana Lau J., Ximena Sepúls.c. veda O., Tabasco, textos de su historia, México,Villahermosa, Instituto de Investigaciones Dr. José Ma. Luis Mora/Gobierno del Estado de Tabasco, 1985, 2 vols. (Biblioteca Básica Tabasqueña. Serie Antologías, 7)

Esta antología proporciona una visión integral de la historia del estado, desde fines del siglo'XVIII hasta la segunda década del XX!Los textos originales, provenientes de autores en su mayoría tabasqueños, relatan aspectos políticos, económicos, costumbristas, geográficos, etc. La obra contiene 20 capítulos, un abundante aparato crítico y un apéndice biográfico de los autores antologados.

INAH

LBS

F1351

B78

BNAL

C

920.97262

BUL.a
Bulnes, Pepe, La Agenda tabasqueña, s.l., s.e.; 1955. $250 \mathrm{p}$.

Preocupado por dar a conocer a los tabasqueños que "trabajan para producir en provecho de la economía del estado", Bulnes recopila en este directorio temas tan diversos como los gobernadores que ha tenido Tabasco entre 1821 y 1914 , la siembra y la cosecha de algunos productos agrícolas, los teatros. las 8 
constituciones locales y toda aquella información que considera útil.

BNAL

928.0972

Bulnes, Pepe, pról. Manuel González Calzada, LiSAN.b cenciado Manuel Sánchez Mármol, México, B. Costa Amic, 1974, 44 p.

Bulnes, con la intención de rescatar del olvido la vida y obra de uno de los grandes exponentes del republicanismo tabasqueño, escribe la biografía de Manuel Sánchez Mármol, nacido en Cunduacán en 1839 y fallecido en la ciudad de México en 1912.

Está dividida en seis capítulos, de los cuales el autor dedica los dos primeros a describir la actuación política de Sánchez Mármol y los siguientes a su labor como novelista, jurisconsulto y académico, dándonos a conocer la trayectoria de quien, a decir del biógrafo, fue el autor del Informe que Gregorio Méndez envió al ministro de Guerra en 1867 y que resulta consulta obligada para quien desee conocer loś sucesos de Tabasco durante la ocupación francesa.

Bulnes hace, además, un esbozo de las obras literarias de Sánchez Mármol entre las que destaca Antón Pérez y Previvida. Menciona también su monografía Estado actual de las letras mexicanas (1902), obra que le abrió las puertas de la Academia Mexicana de la Lengua.

El autor no puede sustraerse a su estilo vivaz y anecdótico por lo que cada asunto que toca está redondeado con gran información al respecto.

BIM

920.07263

BUL.t

CICOM

s.c.

Bulnes, Pepe, Tipos tabasqueños, 2a. ed., México, Industria Gráfica Editorial Mexicana, 1981, 416 p.

Obra literaria que, en prosa y con algunos versos cuenta la biografía de cincuenta personajes común y corrientes. Narración de lo propio; visión psicológica, costumbrista y social, se centra especialmente en Villahermosa. Los "tipos" o el mismo Bulnes, relatan diversos momentos históricos (invasión norteamericana, intervención francesa, pugnas de partidos locales, porfiriato, revolución, años veinte, etcétera).

El autor se sustenta en documentos primarios (decretos) y pasajes bibliográficos (fuentes secundarias), pero no cita los textos que manejó. El libro contiene una "nota" inicial del Consejo Editorial del Gobierno de Tabasco que habla de Bulnes como periodista y cronista de Villahermosa y da opiniones de revistas y periódicos sobre la primera edición (1939); de ésta, conserva los prólogos escritos por Francisco J. Santamaria y Rafael Dominguez y un comentario del español Alfonso Camín.

BIM

972.63

CAM.t

Campos, Julieta y Enrique González Pedrero, Tabasco: las voces de la naturaleza. Monografía estatal, 2a. ed., México, Consejo Editorial del Gobierno del Estado de Tabasco, 1983, 236 p.

La Secretaría de Educación Pública en 1981 solicitó a cada estado de la República Mexicana que realizara una monografía que sirviera como libro de texto.

Esta olvra responde a dicho objetivo. Consta de trece capitulos. Los dos primeros están dedicados a la geografía; del tercero al décimo primero se presenta una síntesis histórica, parte medular del libro, que 
abarca desde los Olmecas hasta la época posgarridista (1982). El capítulo décimo segundo permite conocer cómo son, a qué se dedican, qué producen y cómo se organizan politicamente los tabasqueños. Por último, reseña biografías de personajes asi como costumbres y habla locales.

Se incluyen estadisticas, una relación de gobernadores, mapas, epígrafes, notas a pie de página y una cronología comparada, que se inicia en 1200 a.C. y termina en 1976 . El aparato crítico es rico: bibliografía, hemerografia, leyes y documentos.

BIM

917.2629

CAR.m.

Cárdenas, José Eduardo de, Memoria a favor de la Provincia de Tabasco, Introd. Jorge Gurría Lacroix, México, Consejo Editorial del Gobierno del Estado de Tabasco, 1979, 102 p. (Serie Historia, 6)

El autor de este texto, presbitero cunduacanense y diputado a las Cortes de Cádiz (1811), presenta las demandas locales y las quejas de los habitantes en contra de la sujeción de Tabasco a la provincia de Yucatán. Expone la historia colonial, algunos antecedentes prehispánicos, características geofísicas y humanas. Es interesante mencionar que el autor se considera "español de Tabascó" y recalca su fidelidad a Fernando VII.

La memoria... cuenta con dos partes principales de veintitrés puntos cada una que se relacionan entre sí. El aparato crítico es casi inexistente; Cárdenas hace comparaciones con las culturas grecolatina y medieval.

HNAL

s.c.

Carrascosa, Romualdo, "Estadística General de la Sierra", en Boletín de la Sociedad Mexicana de Geografia y Estadistica, México, Imprenta de A. Boix,

1a. época, vol. 7,1859 , p. $361-381$

A mediados del siglo XIX, el gobierno encargó al agrimensor Romualdo Carrascosa que elaborara la cartografía del estado de Tabasco. En 1854 apareció una minuciosa estadística que describe el distrito de la Sierra, que entonces estaba compuesto por los partidos de Teapa, Tacotalpa, Jalpa y pueblos que los componian; en la actualidad incluye también a Macuspana.

El trabajo contiene datos acerca de la posición geográfica del distrito, su extensión, límites, ríos y montañas, describe la fauna y la flora, se refiere a la temperatura y a las enfermedades, pasando luego a delinear minuciosamente cada uno dé los pueblos.

La lectura de este texto nos brinda la oportunidad de conocer dicho distrito desde el punto de vista de alguien de esa época, de ahí su importancia y utilidad.

BNAL

972.62

CAR.e

Carvajal, Francisco, Exposición del representante del gobierno de Tabasco en la controversia sobre límites con Chiapas (abril 15, 1908), Villahermosa, Cia. Editora Tabasqueña, 1951, 229 p.

Alegato de Francisco Carvajal, representante del estado de Tabasco ante Porfirio Díaz, que fungió como árbitro en el conflicto de límites con Chiapas. Es una defensa de la integridad territorial tabasqueña, que examina los aspectos políticos, históricos, geográficọs, sociológicos, económicos y morales. Demuestra un estudio serio y concienzudo. Tiene conclusiones y aparato crítico. 
BNAL

923.572

1980
COF.g

Coffin, José, Ignacio Gutiérrez, México, Consejo Editorial del Gobierno del Estado de Tabasco, 1980, $186 \mathrm{p}$.

Es una apología a Ignacio Gutiérrez, uno de los precursores del movimiento revolucionario en $\mathrm{Ta}$ basco. Fue escrita poco después de su muerte y publicada en Paraíso, Tabasco, en 1912.

En forma novelada, el autor aporta datos interesantes sobre este personaje poco conocido, cuyo origen social le hizo compartir las penalidades de los campesinos y le llevó a tomar conciencia de la situación del peonaje; describe cómo Gutiérrez organizó a un grupo de oposición con cuyó apoyo se levantó en diciembre de 1910 y los combates en los que intervino, así como su muerte en la batalla de Aldama.

BIM

s.c.

Correa, Alberto, Reseña económica del Estado de Tabasco, México, Consejo Editorial del Gobierno del Estado de Tabasco, 1981, 144 p.

El propósito del texto era responder a la política económica del Porfiriato, dando a conocer las riquezas naturales con que contaba el estado para atraer fuerzas exteriores que activasen la productividad.

El libro cuenta con treinta y tres capítulos divididos en cuatro partes: el medio físico, los recursos naturales, el elemento político y el desarrollo económico. Contiene buena información aunque a veces sus descripciones de la situación del estado son algo idílicas; expone problemas y sus posibles soluciones, como en el caso de la agricultura; hace una relación de los diversos cultivos y de las perspectivas que tienen para desarrollarse. Contiene un directorio de los principales agricultores de la zona y uno mercantil.

Carece de bibliografía y omite las fuentes de donde obtuvo sus datos. La primera edición es de 1899.

BNAL

M868.4

DOM.t

1980

Domínguez, Rafael, Tierra mía, México, Consejo Editorial del Gobierno del Estado de Tabasco, 1980. $325 \mathrm{p}$.

Explica el autor que su fin no es hacer una historia de Tabasco ya que nunca ha guardado apuntes ni recortes pero "haré lo que he hecho en otras ocasiones... hablaré sólo de lo que ví y sentí en la tierruca desde que tuve conciencia de mi vida, aunque estas páginas estén consagradas casi por entero al Tabasco de ayer... Hablar de la provincia, de su tradición, de su vida intima y dulce, de sus hombres, de su música, de sus periódicos..."

La obra consta de 27 capítulos y un epílogo. En uno de sus capítulos trancribe el folleto del Lic. Lorenzo Casanova "Final de un compañerismo" en el cual el autor explica su distanciamiento del Dr. Manuel Mestre Ghigliazza y su separación de la Liga Democrática Tabasqueña, asi como la respuesta a este escrito, llamado "A caza de gazapos políticos" del profesor Alfonso Caparroso. El capítulo finai se refiere a las figuras más importantes de Tabasco, con una pequeña biografía de cada una de las personas mencionadas. La primera edición de la obra de Dominguez data de 1949; ésta de 1980 es un facsimilar. 
BNAL Domínguez Vidal, Mario J., Las selvas de Tabasco. 972.09 - Orígenes de la Revolución de 1910 y 1913, México, DOM.s. $\quad$ Editoral Polis, 1942, 232 p.

Dice el autor que "no es novela porque su argumento es histórico".

Sin embargo, no es una autobiografía, pues aunque narra hechos y evoca cosas que vió, vivió y sintió, Domínguez se vale de un personaje que relata a otro su participación en las luchas revolucionarias de Tabasco. Se destaca más que nada la actuación del general Luis Felipe Domínguez.

Una buena parte de la obra se refiere a la vida en el estado, al porfirismo, a las selvas tabasqueñas, todo a manera de un relato novelado. Del mismo modo describe el triunfo de la revolución constitucionalista, la toma de San Juan Bautista, el traslado de las fuerzas dominguistas a Yucatán y las dificultades con Greene.

En lo general trata los mismos temas y hace las mismas afirmaciones que en su Brigada Usumacinta, concluye con una vuelta al presente, a la época de Avila Camacho, del que dice que sus tendencias se encaminaban a consolidar las conquistas de la Revolución.

No hay bibliografía; cuenta con algunas notas a pie de página en las que el autor aclara algunos términos del lenguaje o costumbres de la población.

BNAL

REV

972.092 .5

DOM.b.

Dominguez Vidal, Mario J., 1910 a 1920 Brigada Usumacinta, s.p.i., 198 p.

El autor justifica su escrito diciendo que por lar: go tiempo guardó silencio ante las injusticias hechas a los revolucionarios de la Brigada Usumacinta, y en particular a Luis Felipe Domínguez, a quien muchos escritores pretendieron eliminar como partícipe de la Revolución sin que Dominguez Vidal se explique cuál fue la razón. Llegó a la conclusión de que "lo escrito en este libro, algún día tendrá que ser pasado por el tamiz de la historia, y si lo falseo, quedaré en el concepto de un mentiroso..." Hace algunas afirmaciones de las que otros autores dudan.

Carece de bibliografía; cuenta con notas a pie de página en las que expone hechos relacionados con la vida de su padre.

Es una obra que busca la reivindicación del biografiado. Termina con una relación de los oficiales muertos en campaña.

BNAL Enríquez, Felipe B., "Comalcalco. Reminiscencias 972.6200 - de mi niñez. Apuntes históricos de 1860-1863", en SAN.d. $\quad$ Francisco J. Santamaria (compilador), Documentos Históricos de Tabasco, Villahermosa-México, Publicaciones del Gobierno del Estado, 1950, p. 87-97.

Estas páginas son remembranzas del autor sobre su actuación como correo de los liberales y de cómo vivió los días agitados del desembarco francés en Frontera y el posterior amago al estado. Los recuerdos de las noticias sobre la pérdida de San Juan Bautista y el ascénso de Arévalo al gobierno se mezclan con menudencias cotidianas y se acompañan con el modo en que, desde la clandestinidad, se organizaron las fuerzas rebeldes encabezadas por Gregorio Méndez, que desde Comalcalco, en octubre de 1863 , salieron a combatir al invasor. 
BIM

s.c.

BNAL

972.62

Gil.c.

1979

Gil y Sáenz, Manuel, Compendio histórico, geográfico y estadístico del estado de Tabasco, Notas Rómulo Becerra Fabre y Justo Cecilio Santa Anna, 2a. ed., México, Consejo Editorial del Gobierno del Estado de Tabasco, 1979, 414 p. (Serie Historia, 7)

Texto de autoridad en la historiografía tabasqueña. Esta edición comprende una "explicación necesaria", anónima; datos biográficos de Gil, realizados por Manuel Mestre Ghigliazza, facsimilar del texto original (1872) con prólogo y tres partes (geografia, historia y estadística) escritos por Gil, y tres apéndices correspondientes a la parte histórica, que son las anotaciones de becerra y Santa Anna; además cuenta con un índice general.

Gil destinó la obra a la juventud tabasqueña con fines didácticos. Distribuyó las tres partes del Compendio... en "lecciones", las de geografía e historia contienen cuestionarios y respuestas. La mayor parte del texto es de historia; trata desde "antiguos tabasqueños" a "nuestros días" (1872).

Las reseñas sobre geografía, educación, economía, religión, etc., son fundamentales.

Las "anotaciones", de gran valor heuristico e interpretativo, corrigen y aumentan el Compendio... En ocasiones, Becerra y Santa Anna recurrieron a "respetables ancianos" por falta de archivos. El aparato crítico de estos dos, como el de Mestre, es rico en el manejo de bibliografía, decretos, cartas, memorias y hemerografía. Gil utilizó principalmente bibliografia; en su prólogo señaló: "como nuestra historia está enlazada con la de Yucatán, nos ha parecido conveniente valernos de varios historiadores de aquélla".

BIM

972.63

DOC.pa

CICOM

s.c.
González Calzada, Manuel, (compilador), Documentos para la historia de Tabasco, México, Consejo Editorial del Gobierno del Estado de Tabasco, 1979, 8 vols. (Serie Historia, 1-2 y 11-16)

El objetivo de esta compilación es cubrir la ausencia de materiales sobre la etapa colonial y años que coinciden con el movimiento de independencia;

fuente de primera mano para conocer la épocas en que la provincia de Tabasco estuvo bajo el dominio español. Aun cuando de temas diferentes, se sigue un orden cronológico en cada tomo.

Los documentos son de orden politico, económico, social y eclesiástico. La obra se presenta en dos series. La primera consta de 6 volúmenes con 4 tomos que abarcan de 1576 a 1820 . La segunda está conformada por 2 tomos que van de 1612 a 1788 . Cuenta con índice; los primeros tomos de cada serie tienen introducción del compilador; algunas veces encontramos mapas y tablas.

La información de fichas fue adquirida originalmente por Luis Chávez Orozco en el Archivo General de la Nación. A su muerte, esas fichas pasaron al Centro de Estudios de Historia de México, Condumex, de donde se obtuvo una copia para realizar la compilación.
González Calzada, Manuel, Historia de la Revolución Mexicana en Tabasco, México, Consejo Editorial del Gobierno del Estado de Tabasco, 1981, 192 p. 
Al presentar su libro González Calzada aclara que se ha concretado, hasta donde le fue posible, "a tratar el tema desde el punto de vista del concepto moderno de la historia... que impide en todo trabajo de historia la concurrencia de hechos menudos y, por lo tanto múltiples, que sólo ocupan los tiempos del autor y del lector sin aportar nada... tales hechos quedan para los cronistas..."

La obra está dividida en siete capitulos, con una escueta bibliografia. Se inicia con la Ley Agraria de Gregorio Méndez de 1864 para explicar la situación social del Tabasco de fines del porfiriato, y concluye en 1919.

En lo general, el escritor expone, basado en documentos y en otros autores, el desarrollo de la revolución en el estado. Utiliza la transcripción de párrafos completos de los materiales antes citados, sin indicar a pie de página la ficha correspondiente. Emite sus propios juicios valorativos pero falta análisis.

BIM

333.33

González Calzada, Manuel, El agrarismo en TabasAGR.t co, México, Consejo Editorial del Gobierno del Estado de Tabasco, 1980, 202 p.

Los textos que se rescatan y reproducen en esta obra fueron publicados en la revista El Progreso, órgano de la Cámara Nacional Agrícola de Tabasco entre 1911 y la Decena Trágica. Algunos títulos reflejan la importancia de los artículos incluidos: "el peonaje en el campo y la actitud del gobierno"; "la distribución de las tierras"; "sobre el peonaje de campo en Tabasco"; "el fraccionamiento de tierras..."

González Calzada considera el problema de la tierra como un factor determinante para el desarrollo del movimiento revolucionario. Señala que después del decreto que liberó a los peones no se hizo mucho; una vez sentadas las bases jurídicas del movimiento, no se volvió a hablar del problema agrario, sino hasta el gobierno de Garrido Canabal.

\section{BIM}

923.27263

MES.go

CICOM

s.c.

Manuel Mestre Ghigliazza en la historia política de Tabasco". En el primero el autor analiza el porqué de los nombres exóticos de los tabasqueños y presenta reflexiones e información sobre las carencias culturales y las manifestaciones literarias en el estado.

En el segundo capítulo, González hace un juicio crítico en torno a la ambigua figura politica de Mestre, y expone sus errores. Las conclusiones, que se dan sólo en esta parte, se inclinan hacia la condena, aunque luego intentan reivindicar a Mestre comö hombre de letras y compilador.

El autor se valió de fuentes primarias (informes de gobierno, discursos, documentos, una carta y hemerografia) y secundarias (monografias, ensayos, diccionarios, etc.); manejó apuntes autobiográficos de Mestre y se autocita. La obra de carácter cultural, anecdótico y político cuenta con buen aparato crítico e interpretación histórica. 
BNAL

972.62

GUR.m.

$\mathrm{BIM}$

972.62

GUR.m.
Gurría Lacroix, Jorge, "La Intervención y el Imperio en el estado de Tabasco', , en Monografías históricas sobre Tabasco, Tabasco, Publicaciones del gobierno del Estado de Tabasco/Instituto de Historia UNAM, p. 1952, p. 141-215 (Escritores Tabasqueños, 72).

El estudio contiene datos que se apoyan en bibliohemerografía de la época, por lo que resulta valioso para conocer cómo el estado de Tabasco fue ocupado por tropas francesas, gobernado por un aventurero impuesto por el invasor y la forma en que se organizó un ejército popular para desalojar a los intervencionistas.

Si bien en sus conclusiones Gurría considera este capítulo de la historia tabasqueña como de "poca importancia y significación estratégica" por ser sólo un hecho aislado que no influyó en la situación general del país, para los actores del drama el suceso fue significativo ya que contribuyó al fortalecimiento de la unidad estatal.

A pesar del pesimismo del autor, el estudio es completo, interesante y bien documentado porque relaciona el acontecer nacional con el regional.

\section{BNAL \\ 972.62 \\ GUR.m. \\ BIM. \\ 972.62 \\ GUR.m. \\ Gurria Lacroix, Jorge, Monografías Históricas sobre Tabasco, Tabasco, publicaciones del gobierno del es- tado de Tabasco/Instituto de Historia, UNAM ,1952, 233 p. (Escritores tabasqueños, 72). \\ Estos escritos sobre temas tabasqueños son un aporte que el historiador Gurría ofrece a su tierra natal. En ellos se tratan asuntos de arqueología de la conquista y de la evangelización. Habla también acerca de la época del nacimiento de la República a través de la figura de José Maria Alpuche e Infante. \\ Para sustentar sus análisis Gurria utiliza una numerosa biblioheme- rografía.}

BNAL

REV

972.62091

HER.d.

INAH

F220

$\mathrm{H} 4$

Hernández Ferrer, Atonio, Domingo Borrego y el civismo en Tabasco (Capítulos de la Revolución), Méjico, Ed. Cultura, T. G., S. A., 1951, 188 p. (Publicaciones del Gobierno del Estado de Tabasco, 69).

Es una apología de Domingo Borrego, "símbolo del civismo tabasqueño", de quien se reseña la infancia, educación, toma de conciencia y oposición al gobierno de Abraham Bandala y por consiguiente al de Díaz, haciendo hincapié en este asurito. Narra su amistad con Manuel Mestre Ghigliazza, la organización de la Liga Tabasqueña, su papel como gobernador interino del estado al triunfo del maderismo y la entrega del poder a Manuel Mestre, primer gobernador electo en forma popular. Finaliza haciendo un recuento de los cargos públicos ocupados por Borrego.

El libro carece de bibliografía; contiene un apéndice de versos, fruto de la pluma del biografiado. 
BNAL

972.09:868

IDU.n.

Iduarte, Andrés, Un niño en la Revolución mexicana, México, Ed. Ruta, 1951, 166 p. (Temas Mexicanos, 14).

Fresca y amena, la obra de Iduarte plasma los recuerdos de su niñez durante la época de la revolución, de 1910 hasta 1920. Es rica en descripciones de la vida diaria de su familia y de la gente de Villahermosa, y profunda al hablar de la idiosincrasia del tabasqueño. El autor nos cuenta el paso de la Revolución en su gente, la ciudad, el estado y su propia vida; refleja asimismo el cambio que sufre en su sentir y pensar. Toca temas de la vida social, las costumbres, los prejuicios, la revolución, los bandos antagónicos, etc. Debido a que Iduarte conoce bien el alma del tabasqueño, la obra es un buen estudio sicológico. Consta de 16 capítulos.

$\mathrm{BM}$ (FB)

972.62

L297e

C.B.

BNAL

040.08

UNAM. 1

1936

Lanz Margalli, Luis, Efemérides de Tabasco, México, Tesis de maestría, Facultad de Filosofía y Estudios Superiores, Sección de Ciencias Históricas, Universidad Nacional de México, 1936, 208 p.

El autor explica en la introducción que su objetivo era escribir unos apuntes históricos sobre su estado, desde la época prehispánica hasta sus días; que consultó "todas" las obras existentes y se convenció de que su tarea era imposible mientras no se completaran los estudios arqueológicos y no se exploraran los archivos de Indias en Sevilla.

Las Efemérides fueron entonces el producto de un proyecto que no se llevó a cabo.

Se destacan acontecimientos históricos y biográficos; expedición, promulgación y publicación de leyes y decretos, desde 1493 hasta 1930 todo ello ordenado por meses. Lanz quiso facilitar la labor del biógrafo, del historiador y de la gente interesada en su terruño; sin embargo, su difícil manejo las hace de poca utilidad. Incluye algunas fuentes.

HNAL

s.c.

León, Juan José, "Apuntes muy interesantes para servir a la estadistica de Tabasco", en Boletín de la Sociedad Mexicana de Geografia y Estadística, México.

Imprenta de A. Boix, la. época, vol. 8, 1860, p. 424-437.

Escritos a manera de diario entre 1860 y 1862 en la villa de San Antonio de Cárdenas, estos apuntes fueron publicados como memorias de estadística para que sirvieran de base en la "formación de un cuadro sinóptico de los elementos productores de la República Mexicana".

Las anotaciones del doctor en medicina León giran alrededor de temas tan dispersos como el comercio interior, el tabaco, la geografía histórica, la lengua, las enfermedades dominantes (que trata más extensamente) así como aspectos relativos a precios de mano de obra y jornales, caminos, calzado, etcétera.

Ante la escasez de fuentes de primera mano para el estudio del estado de Tabasco, estas noticias nos permiten conocer, aunque en fragmentos, algunos aspectos de la economía. 
BNAL

972.62

LOP.h

López Reyes, Diógenes, Historia de Tabasco, México, Consejo Editorial del Gobierno del Estado de Tabasco, 1980, 541 p. (Serie Historia, 25)

Este trabajo narra en detalle los acontecimientos desde tiempos remotos hasta 1958; en lo general presenta su exposición año por año. Su mérito consiste en aportar datos concretos del estado en intima relación con los del devenir nacional y breves noticias biográficas, por lo que resulta una obra de consulta fundamental.

El cuerpo del texto se estructura con una "información necesaria" de Manuel González Calzada y un "prefacio" de Eva López de Shelton; nueve capítulos y un apéndice sobre gobernantes.

El autor se valió de abundantes documentos, de fuentes primarias y secundarias; se sustentó principalmente en el texto de Manuel Gil y Sáenz y en la compilación de Manuel Mestre Ghigliazza. La obra contiene pocas notas a pie de página.

CONDUMEX López Reyes, Diógenes, "Tabasco ante la invasión 082.1

SOC.

A.No. $\mathbf{5 2 0 0}$ de su territorio por fuerzas intervencionistas en 1863-1864 a 1867", en Linares, Sinaloa, Durango, Tabasco y Chiapas en la Guerra de Intervención. México, Sociedad Mexicana de Geografía y Estadística, 1963, p. 123-129 (Colección del Congreso Nacionạl de Historia para el estudio de la guerra de intervención, 27)

Artículo que narra cronológica y concisamente los hechos ocurridos en Tabasco desde el 21 de febrero de 1863, cuando los franceses se presentan frente a San Juan Bautista exigiendo la rendición de la plaza, hasta que abandonan el puerto de Frontera en noviembre de 1866.

El autor hace referencia a periódicos de la época como sustento de sus aseveraciones pero no analiza las situaciones que refiere.

BNAL Méndez, Gregorio, Reseña oficial de los sucesos del $\mathbf{R}$ estado de Tabasco en los órdenes militar y político du972.62 rante la intervención extranjera dirigida al supremo MEN.r . gobierno de la República, San Juan Bautista, Tip. del Gobierno, 1904.

Este interesante documento que el coronel Gregorio Méndez envió al ministro de Guerra, Ignacio Mejia, el 17 de octubre de 1867, es la mejor fuente de información que poseemos acerca de las batallas que li- braron los tabasqueños para expulsar a los franceses de su territorio.

El informe pormenorizado hasta en sus más nimios detalles, describe fielmente los episodios, sin omitir nombres, lugares ni fechas.

Según Pepe Bulnes la redacción del documento estuvo a cargo del Lic. Manuel Sánchez Mármol, en su calidad de secretario particular de Gregorio Méndez.

$\begin{array}{ll}\text { BNAL } & \text { Merino Garcia Manuel, Ruta. Novela histórica, San } \\ \text { M863.3 } & \text { Juan Bautista, Talleres de Tipografía, Litografía / } \\ \text { MER.r. } & \text {.. / González, 1907, 214 p. (Biblioteca de autores ta- } \\ & \text { basqueños). }\end{array}$

A partir de la historia de Rutilia, apodada Ruta, mujer casquivana y frívola, el autor refiere trozos de la historia de Tabasco; principalmente de los años treinta a cincuenta del siglo pasado, resaltando la figura de Miguel Bruno y la invasión norteamericana. Se remonta al prehispánico y a la conquista. 
Los fines son didácticos y moralistas; se alude a la Historia como tribunal, se ataca a los conservadores (clero y militares) y a gente "sin principios"; los personajes reales y ticticios que se alternan en Ruta..., se desenvuelven en forma maniquea.

La novela consta de una carta del autor, un prólogo de Felipe A. Margalli (con poemas y acrósticos) y 40 capítulos. Merino hace analogías con la mitología griega; menciona o cita a Bernal Díaz del Castillo, Hernán Cortés, Sor Juana Inés de la Cruz, Chateaubriand y Shakespeare, entre otros, e inserta artículos periodísticos, fragmentos bibliográficos, oficios de gobernadores, apuntes biográficos y otros materiales de primera y segunda mano. Al final introduce indices onomástico y de grabados y un apéndice con documentos de 1857 a 1886. La primera edición, del Instituto de Historia de la U.N.A.M,data de 1948.

BIM Mestre Ghigliazza, Manuel (compilador), Invasión

972.63 norteamericana en Tabasco, (1846-1847), Documentos, 2a. ed., México, Consejo editorial del MES.i Gobierno del Estado de Tabasco, 1981, 365 p. (Serie Historia, 33).

Como el mismo Manuel Mestre expresa, la obra intenta “...ilustrar la historia... sobre lo ocurrido, política y militarmente, en mi estado natal durante la invasión norteamericana de 1846-47. El lejano, y en cierto modo, pobre Tabasco, tuvo su parte en tan desventurada pugna, y es justo y conveniente no dejar en el olvido lo que en aquel entonces ocurriera en su suelo... más que trazar un relato, aun sobrio, de los sucesos, importa sobre todo presentar reunidos documentos y datos, por insignificantes que sean... para que así abierto y allanado el camino, pueda quien posea talentos de historiador expresar y comentar debidamente...".

Mestre no se detiene en 1847, incluye el conflicto que se desató al año siguiente entre Miguel Bruno y Tomás Marín porque ambos deseaban la comandancia del estado.

En los 14 capítulos del texto, se presentan noticias biográficas de varios personajes como Juan Bautista Traconis, artículos de periódicos, oficios, partes, proclamas, etc. y fragmentò bibliográficos que permiten conocer aquel momento.

El aparato crítico es rico por el manejo de fuentes primarias y secundarias. Existen indices onomástico y de grabados, y un apéndice que reivindica a Bruno, años después de su muerte.

\section{BIM}

923.27263

MES.g.
Mestre Ghigliazza, Manuel, Gobernantes de Tabasco, 1821-1914, 2a. ed., México, Consejo Editorial del Gobierno del estado de Tabasco, 1982, $381 \mathrm{p}$.

Fuente útil para conocer quiénes estuvieron en el poder en Tabasco entre 1821 y 1914. Fue escrita con el propósito de subsanar los errores "involuntarios" que aparecieron en el Compendio histórico-geográfico de Tabasco de Manuel Gil y Sáenz y en la Relación de los gobernantes de Tabasco, (1909) de Gregorio Hernández de Dios y Manuel Diaz Prieto.

Basándose en la hemerografía de la época, el autor rectifica fechas y acontecimientos sobre los que hay dudas; además, presenta retratos, partidas de nacimiento y defúnción de-eada gobernador. La obra comienza con una autobiografía. 
BIM

972.63

DOC.y

1984

Mestre Ghigliazża, Manuel (compilador), Documentos y datos para la historia de Tabasco, México, Universidad Juárez Autónoma de Tabasco, 1984, 4 vols.

Compilación básica para conocer el proceso histórico tabasqueño de 1790 a 1845 . Mestre dedicó parte de su vida a investigar y rescatar materiales primarios y secundarios; además de algunos que le fueron obsequiados, adquirió otros de archivos personales y familiares, de hemerotecas y bibliotecas de otros estados y de las nacionales, así como del Archivo General de la Nación.

A través de cartas y relatos de viajeros, artículos hemerográficos, decretos, informes, estadísticas, reglamentos, etc., se nos permite reconstruir los diversos aspectos de la vida tabasqueña. El aparato crítico, las notas aclaratorias y complementarias, y las introducciones, son de valiosa utilidad. Cada volumen cuenta con introducción, apéndice e índice onomástico; los capítulos están dispuestos por año. La primera edición fue de 1916 (vol. 1), 1920 (vol. 2), 1924 (vol. 3) y 1940 (vol. 4).

A continuación se reseñan cuatro textos que Mestre incluye en su obra y que deseamos resaltar debido a su importancia.

BIM

972.63

DOC.Y

1984

"1833-1834. El barón de Waldeck en Tabasco", en Manuel Mestre Ghigliazza, (compilador), Documentos para la historia de Tabasco, México, Universidad Juárez Autónoma de Tabasco, 1984, vol.2, p. 85-107

Waldeck escribió Voyage pittoresque et arquéologique dans la Province d'Yucatán (Amérique Centrale), pendant les années 1834 et 1836, par Frédéric de Waldeck, dédié a la mémoire de feu le Vicomte de kingsborough, (París, 1838). La parte referente a Tabasco fue traducida y anotada por Mestre; en una de las notas se presentan los datos biográficos del barón. .

Originalmente la obra fue diario de viaje. Relata la estancia de Waldeck en frontera y San Juan Bautista, de diciembre de 1833 a mayo de 1834.

Anota sus impresiones sobre el cólera morbo; refiere la lucha entre el aspirante a gobernador Santiago Duque de Estrada y el inspector de milicias; Nicolás Maldonado. Critica y caracteriza lo que es una "revolución en América Meridional y Central". Observa el culto al Señor de Esquipulas y censura al clero local. Por otro lado, habla sobre el traslado del ganado vacuno a través del río Grijalva y la fauna de éste.

\section{BIM}

972.63

DOC.Y

1984

"Nota estadística remitida por la Legislatura del estado de Tabasco a la Cámara del Senado del Soberano Congreso General, conforme a lo prevenido en el artículo 32 del Acta Constitutiva y 161 número 8 de la Constitución Federal, año de 1826", en Manuẹl Mestre Ghigliazza, (compilador), Documentos y datos para la historia de Tabasco, México, Universidad Juárez Autónoma de Tabasco, 1984, vol. 1. p. 295-308

La estadística se inicia con datos de 1823 y se sustenta en los padrones de ese entonces.

Es fundamental para tener una idea de la economia de aquellos años. Contiene cinco apartados: "Hacienda Pública del Estado", "Industria Agricola", “Mercantil" “Fabril"'y "Población"; se adjuntan cuatro tablas que manifiestan los ingresos y egresos, los gastos ordinarios y extraordinarios, las introducciones y extracciones de productos; los de- 
partamentos, partidos, pueblos adyacentes, iglesias, familias, número de habitantes, haciendas de ganado, de agricultura y sitios pequeños de ambas clases.

Mediante estas tablas podemos comparar cuantitativamente y destacar la importancia de algunos lúgares como Cunduacán.

Fue firmada en 1826 por José Mauricio Ferrer, presidente de la Legislatura local y por Manuel Padrón y Rudecindo Maria Hernández, quienes fungian como diputados secretarios.

\section{BIM}

972.63

DOC.y

1984

Zapata Zavala, Manuel "Apuntes estadísticos sobre el Departamento de Tabasco...", en Manuel Mestre Ghigliazza (compilador), Documentos y datos para la historia de Tabasco, México, Universidad Juárez Autónoma de Tabasco, 1984, vol. 3. p. 329-346

Artículo que fue publicado en el periódico El Siglo Diez y Nueve de la Ciudad de México, en abril de 1842. Manuel Mestre, al reproducirlo, lo acompaña de un "Remitido" que apareció días antes en dicho periódico, en el que se nos hace saber que Zapata Zavala tuvo por objeto rectificar errores sobre el departamento de Tabasco al que se consideraba inhabitable, enfermizo y sumido en la ignorancia; además, era su intención darlo a conocer en la República y en el extranjero.

La mayor parte del artículo fue producto de la observación directa del autor, yucateco que radicó durante 23 años en diversos lugares del entonces departamento de Tabasco, donde fue haciendo sus "apuntaciones". Zapata Zavala alude al manejo de la obra de Humboldt y aclara que recogió noticias documentales cuando trabajó en el gobierno tabasqueño.

Presenta la visión geográfica, educativa y económica (distribución de la propiedad, comercio, infraestructura, rentas, etc.) de la primera mitad del siglo pasado.

BIM

972.63

DOC.y

1984
Zapata Zavala, Manuel, "La Villa de Teapa", "El río Usumacinta" y "Las inundaciones de Tabasco", en Manuel Mestre Ghigliazza, (compilador), Documentos y datos para la historia de Tabasco, México, Universidad Juárez Autónoma de Tabasco, 1984, vol. 3. p. 615-618, 623-627 y 632-637.

Estos articulos son observaciones del autor, viajero que reseñó los aspectos geográfico, económico y humano de diversas zonas tabasqueñas. Fueron publicados originalmente en la obra de Ignacio Cumplido, El museo mexicano, o miscelánea pintoresca de amenidades curiosas e instructivas (tomo 2) en 1843.

En el primer artículo, Zapata Zavala recrea el paisaje natural y arquitectónico de la Villa de Teapa. Presenta someras características de su riqueza agrícola; refiere el número de habitantes y algunas de las actividades y costumbres del "pueblo más sano" del departamento.

El segundo describe la zona bañada por el río Usumacinta y sus tributarios; la riqueza de su fauna y flora, sus maderas preciosas y plantas medicinales. El autor contrasta la belleza con la fuerza de ese "monstruoso gigante" que abrió brechas, arrastrando lo que halló a su paso, desde las sierras de Chiapas.

El tercero pincela los límites y el terreno del departamento. Comparando con Egipto, Zapata Zavala habla de la periodicidad de los desbordamientos ribereños, de cómo en octubre Tabasco es un gran lago y de 
cómo las inundaciones son fundamentales para el riego, el tránsito y comercio interior. Aunque fatales para los animales, las inundaciones son "divertidas y útiles" para los lugareños; así, el autor propone que, si hay previsión, de la adversidad viene la ganancia; lo que en otras partes es temor y calamidad, en Tabasco es interés y beneficio.

TMRM

Muñoz Ortiz, Humberto, Biografía de una ciudad (su

s.c. tiempo y sus hombres 1519-1975) Santa Maria de la Victoria. La Villa hermosa de San Juan Bautista, Vi-

BIM llahermosa, s. e., 1975.

s.c.

El autor explica que su obra "es una recopilación sintética de lo que en el transcurso de los años se ha escrito sobre la capital de Tabasco... casi nada de lo que hay en este libro es nuestro... la biografía la hicieron quienes nos precedieron en el devenir de los años plasmando lo acontecido en su propio tiempo, lo que nosotros hemos recopilado para ofrecérselo en confunto al pueblo de Villahermosa..."

Muñoz Ortiz toma textos de Sahagún, Landa, Bernal Diaz, Gil y Sáenz, Rovirosa, Eduardo de Cárdenas, Barón de Waldeck, Justo Cecilio Santa Anna, Rómulo Becerra Fabre, Justo Sierra O'Reilly, Manuel Mestre Ghigliazza, Pepe Bulnes, Bernardo del Aguila, Francisco J. Santamaría, Rafael Domínguez, Alfonso Taracena, Diógenes López Reyes; entre otros. En el desarrollo mismo del texto, el autor menciona las obras de las cuales seleccionó los párrafos.

HNAL "Noticias estadísticas del partido de Jalpa del des.c. $\quad$ partamento de Tabasco" en Boletín de la Sociedad Mexicana de Geografía y Estadística, México, Imprenta de A. Boix, 1a. época, vol. 7, 1859, p. 382-340.

Comprende una descripción de Jalapa, cabecera del partido del mismo nombre y pueblos que lo componen, entre los que estaban Jalpa, Soyataco, Cupilco, Comalcalco, etc.

Agrupa metódicamente datos de cada pueblo tales como: situación geográfica, vías fluviales, ramos agrícolas e incluso la historia de la fundación de cada lugar y un breve trazo de edificios, haciendas, número de habitantes y forma de gobierno.

Estas noticias aparecieron publicadas sin firma. Los redactores del Boletín... aclaraban que lo imprimian en tanto se formaba una estadística general de Tabasco.

BIM

s.c.

TMRM

s.c.
Reseña geográfica y estadística del Estado de Tabasco. Escrita por acuerdo del C. Gobernador Dr. Simón Sarlat, México, Consejo Editorial del Gobierno del Estado de Tabasco, 1979, 74 p.

El autor de esta obra editada por vez primera en 1890 , es José N. Rovirosa. El texto es un informe breve y conciso que abarca no sólo la descripción del territorio (límites, extensiones, suelos, ríos, clima) sino también la flora y fauna, enumerando las diversas especies, la población (número, lenguas indígenas), la división territorial, judicial, municipal, religiosa, la instrucción. pública, la agricultura, las vías de comunicación, el comercio, telégrafo y correo. En resumen, Rovirosa nos da una visión bastante completa de Tabasco hacia fines del siglo XIX. Ofrece también algunos cuadros y gráficas que ayudan a explicar mejor la distribución de los ingresos y 
egresos de las municipalidades, los ramos en el ejercicio fiscal, las importaciones, navegación, etc.

La obra carece de aparato crítico y bibliografía.

INAH

FTS

3458

Ramirez Garrido, José Domingo, La esclavitud en Tabasco, San Juan Bautista, Talleres Gráficos de Regeneración, 1915, 22 p.

Folleto en el que se analiza brevemente la situación de los peones a fines del porfiriato. Tiene como complemento una explicación de cómo, cuándo y dónde se promulgó el decreto que liberaba a los peones, según el cual Dominguez Garrido tuvo una participación significativa. Al final del texto se reproduce el documento, dado en San Juan Bautista en septiembre de 1914, durante el gobierno interino de Luis Felipe Domínguez.

Carece de bibliografia y aparato crítico.

\section{BNAL \\ REV}

972.09:865

RAM.a

Ramírez Garrido, José Domingo, Alma Tabasqueña, Mérida, Imp. y Linot. de "La voz de la Revolución", $1915,48 \mathrm{p}$.

Opúsculo con tres alocuciones presentadas en Villahermosa entre abril y mayo de 1915. La primera, "A los mártires tabasqueños", es una apología al general Ignacio Gutiérrez y una exhortación a seguir su ejemplo. La segunda, "El alma tabasqueña" critica a la intelectualidad local, las carencias en infraestructura y los medios de información y educación, y la tercera alocución, "Biblioteca José N. Rovirosa", fue dicha con motivo de la inauguración de ésta. Permite apreciar la posición ideológica de Ramírez a favor del peón y del artesáno, contra el alcoholismo y los juegos de azar. Habla de la necesidad de tener bibliotecas públicas. El autor señala "creo haber dado una idea ligera de nuestra idiosincrasia, de lo que constituye el alma tabasqueña en su parte enferma (...)".

La obra es valiosa para conocer al escritor y su momento; está dedicada a Salvador Alvarado, Adolfo de la Huerta, Fernando Iglesias Calderón y Roque Estrada. Contiene aparato critico.

INAH

Z1411

M751

No. 16

BIM

B

015.7208

MBM.1.16

Rovirosa, José Narciso, "El Partido de Macuspana. Monografía histórico-geográfica", en Francisco J. Santamaría, Bibliografia General de Tabasco, México, Secretaría de Relaciones Exteriores, 1930, vol. 1. p. 89-208. (Monografías Bibliográficas Mexicanas, 16).

Siempre atento en la salvaguarda del material referente a Tabasco, Santamaría rescató del olvido esta pequeña obra manuscrita, fechada en 1875 .

Analiza y explica las particularidades de la zona de Macuspana, lugar de donde era originario, y a la que considera "una de las fracciones más importantes de Tabasco".

Enfoca su estudio a describir la topografía y los elementos que pueden traer a su estado y a su partido verdadera prosperidad y adelanto. de ahí su preocupación por difundir las producciones de la tierra, su fauna y su flora, y la importancia que concede al desarrollo agrícola y comercial. 
BNAL

972.62

RUI.r.

CONDUMEX

323.272 .62

RUI

A.No 10642

Ruiz, Joaquin, La revolución en Tabasco, México, s. e., $1934,123 \mathrm{p}$.

En el prólogo, el autor explica que su objetivo es hacer una presentación de los líderes de Tabasco que han lucrado con las demandas de los trabajadores.

En los primeros capitulos, hace brevemente una reseña del desarrollo de la Revolución en el estado y de quiénes la utilizaron en su beneficio. La parte medular de la obra se refiere al gobierno de Tomás Garrido Canabal: desde sus orígenes como hijo de propietarios de tierras, y su participación en el gobierno de Carlos Greene, hasta la imposición de sus ideas en Tabasco y su actuación como lider máximo del estado.

Ruiz denuncia la actuación de Garrido y del enriquecimiento de sus familiares, el despojo a sus opositores, el fanatismo antirreligioso, tanto en él como en sus seguidores. En un capítulo llamado "Asesinatos", se enlistan una serie de muertes atribuidas al garridismo.

El autor se apoya en correspondencia del propio Garrido, reproducida en el libro. No hay bibliografía ni aparato crítico.

HNAL Ruiz de la Peña, Marcos, “Descripción de San Juan s.c. Bautista. Capital del Estado de Tabasco", en El Cronista de México, Semanario Ilustrado Independiente.

México, vol. IV, núm. 103, 21 y 22 de enero de 1882.

Para conocer el estado de Tabasco, esta descripción escrita en 1881 , nos presenta un panorama detallado de lo que existia en la época en San Juan Bautista, actualmente Villahermosa.

El autor nos dice que a causa de las guerras civiles en el estado y de las intervenciones extranjeras, la capital ha sufrido mucho y su progreso ha sido lento; sin embargo prevé un futuro halagüeño debido a su "clima benigno" y a la construcción de nuevas edificaciones.

BNAL

M863.3

SAN. 2

Sánchez Mármol, Manuel, Antón Pérez, 2a. ed., Mérida, Editorial Yucatanense, "Club del Libro", 1950, $196 \mathrm{p}$.

Novela histórica escrita en 1903, que relata los acontecimientos que el literato Sánchez Mármol vivió en su calidad de secretario particular de Gregorio Méndez, durante la invasión francesa en Tabasco.

La intención del autor fue dejar en la memoria de las nuevas generaciones el nombre y los hechos de aquéllos que abandonaron hogar y comodidades por la justicia de su causa; así, desfilan ante nosotros Gregorio Méndez, Sánchez Magallanes, Eusebio Castillo y todos los que sin dinero ni armas dieron prueba de su valor y constancia en el combate por sus ideales.

Si bien una intriga amorosa recorre el relato, es sólo el pretexto para presentar el panorama del estado, desde la descripción de algunos barrios, los hábitos religiosos de la población, el vestuario de aquéllos que simpatizaban con los franceses y el de los que los combatían: los colorados.

La decisión por amor de Antón Pérez de lograr fama y dinero para acercarse a la mujer de sus sueños, tiene el trágico desenlace de quienes reniegan del republicanismo en favor de los tiranos: la derrota y la muerte. 
BIM

630

SAN.n

Santa Anna, Justo Cecilio, Notas para la historia de la agricultura en Tabasco, 1a. ed., México, Consejo Editorial del Gobierno del Estado de Tabasco, 1979, 92 p. (Serie Historia, 8)

Este texto contiene once capitulos que fueron originalmente articulos del autor, publicados en 1906, en la revista semanaria El Progreso. Cuenta además con una introducción escrita por Manuel González Calzada quien, en nuestra opinión, considera la visión económica como la mayor aportación de la obra a la historiografía tabasqueña.

Justo Cecilio Santa Anna manejó algunos documentos y bibliografía de sus contemporáneos y de cronistas españoles para dar a conocer el desarrollo y evolución de la agricultura local y esclarecer dudas al respecto. Refiere el origen prehispánico o colonial, las condiciones físicas, la periodicidad y técnicas de los cultivos. Observa el principio del sistema de servidumbre, del peonaje; la forma de propiedad territorial y las relaciones de producción; el comercio, la ganadería y la industria, hasta los primeros años del siglo $\mathrm{XX}$.

BNAL

398.237262

SAN.t 1979

Santa Anna, Justo Cecilio, Tradiciones y Leyendas Tabasqueñas, 2a. ed., México, Consejo Editorial del Gobierno del Estado de Tabasco, 1979, 183 p.

Esta obra se basa en una serie de artículos que Santa Anna publicó en periódicos y revistas, con el seudónimo de "Maurilio" y de "Rodrigo Canul"

Fundándose en recuentos históricos, tradición popular y alguno que otro documento inédito (a decir del autor), la obra reúne asuntos que fueron del dominio público y que están más del lado de la ficción que la historia, y que seguramente sobrevivieron por transmisión oral.

Por considerarlos susceptibles de caer en el olvido, el autor los rescató. Así, escribe sobre la época de la conquista, de la independencia y de la invasión francesa.

BNAL

B

015.7208

MBM.1.16

INAH

Z1411

M751

No. 16

Santamaria, Francisco J., Bibliografia general de Tabasco, México, Secretaría de Relaciones Exteriores, 1930, vol. 1 (Monografías Bibliográficas Mexicanas, 16).

Texto de consulta y punto de partida para conocer lo que fue publicado de 1821 a 1927 en Tabasco. El autor señala que: "por una verdadera fatalidad (...) los viejos impresos (...) carecen casi siempre de portada o de fin, o de hojas intermedias, o de todo a la vez (...) lo cual es una demostración más del descuido y la poca estima con que se les ha conservado".

En la "advertencia necesaria" se habla de los esfuerzos y dificultades para lograr reunir los materiales, además de mencionar quiénes fueron los impresores más antiguos en la entidad.

El volumen cuenta con una historia de la imprenta local, con la referencia cronológica de los materiales y, al final, con mapas, fotografías, láminas e indice.

En ocasiones se reproducen textos, se hacen reseñas, se apuntan datos biográficos o se agregan comentarios de Manuel Mestre Ghigliazza (principal colaborador de Santamaría).

Se manejaron libros, folletos, periódicos; fuentes primarias y secundarias. Las notas a pie de página además de aclarar y aumentar, nos 
muestran el interés bibliográfico de Santamaria en coleccionar documentos y libros.

\begin{abstract}
BIM
016.97263

SAN.b

v. 2

BIM

016.97263

SAN.b

v.3

Santamaria, Francisco J., Bibliografía general de Tabasco, México, Contribución de Tabasco a la Cultura Nacional, 1945-1946, vols. II y III

Obra del mismo carácter que la anterior, editada años más tarde y con el fin de complementar el proyecto de crear bibliografías de los estados de la República y cuya publicación comienza Genaro Estrada desde 1926.

El volumen II presenta documentos y bibliohemerografía inéditos y reeditados que no fueron inclui-

dos en el volumen de 1930. Cuenta con fotografías, apéndices, notas y rectificaciones de Santamaria (escritas en 1932); una advertencia y palabras finales, contiene escritos de 1825 a 1845 . El volumen III va de 1811 a 1945; consta de apéndice general e índices, expone lo producido por autores tabasqueños y lo relacionado con la entidad pero impresos fuera de ella.
\end{abstract}

BIM Santamaria, Francisco J., El movimiento cultural en s.c. Tabasco. Breviario histórico, / Villahermosa / Gobierno Constitucional de Tabasco, 1945, p. 5-57.

TMRM

s.c.

(Contribución de Tabasco a la Cultura Nacional, 3)

Esta monografia es la conferencia que en 1943 presentó el autor en la ciudad de México ante la Sociedad Mexicana de Geografía y Estadistica. A través de lo que se ha escrito, revisa la "evolución intelectual" del estado durante el siglo pasado y lo que va del XX. Aporta algunos datos biográficos de los autores y distingue el estilo, género y tipo de obra que produjeron.

El texto contiene indice, notas aclaratorias y diez apartados: literatura general, novela, poesía, periodismo, teatro y folklore, historia, geografía, estudios didácticos, estudios lingüisticos y obra diversa. El aparato critico es pobre, menciona a Manuel Gil y Sáenz, a Manuel Mestre Ghigliazza y se autocita.

La parte introductoria es sustanciosa e interpretativa. Resalta el aislamiento de la entidad respeto al centro y que el acontecer local responde al "denominador común" (la historia nacional). Concibe como hechos significativos en la localidad las guerras contra los norteamericanos y contra los franceses, la revolución de 1910, la abolición de la servidumbre, la administración de Tomás Garrido Canabal y el movimiento agrario que culminó con la creación del ejido durante el gobierno de Francisco Trujillo Gurria.

BNAL

M928.6A

SAN.S.

TJM

s.c.

Santamaria, Francisco J., Semblanzas Tabasqueñas, Villahermosa/, Gobierno Constitucional de Tabasco, 1946, 162 p. (Contribución de Tabasco a la Cultura Nacional, 9)

Reúne 63 noticias biográficas por orden alfabético. A manera de epígrafe, el autor anota el lugar y fecha de nacimiento y muerte de los personajes. Algunas de las semblanzas son autobiográficas o fueron escritas por otros autores como Alfonso Taracena.

El texto fue en principio folleto. Contiene notas aclaratorias y está en 
parte sustentado en León Alejo Torre y Rómulo Becerra Fabre. El estilo es romántico; se intercalan poemas y se señala la producción literaria de los biografiados al final de cada uno de ellos.

La introducción, artificiosa apología a Santamaría, fue realizada por Noé de la Flor Casanova. Se advierte que fue utilizada originalmente en 1940, como prólogo, a La Poesía Tabasqueña del mismo Santamaría.

BNAL

972.6200

SAN.d v. 1

Santamaria, Francisco J., Documentos históricos de Tabasco, Villahermosa, Tabasco, Publicaciones del Gobierno del Estado, 1950, 293 p. vol. 1

La obra es una recopilación de 17 documentos de temas varios y fechas diversas. Entre otros se incluyen "Datos para la historia del estado (1814-1864)"; "Apuntes históricos sobre Comalcalco (1860-63)"; "Apuntes biográficos de Carlos Greene"; asuntos de límites, y otros como contratos de alumbrado, ferrocarriles"y muelles; explotación maderera; notas estadísticas; manifiesto de Arévalo; la fundación de Villahermosa, etc. Uno de los documentos que merecen atención aparte es la biografía de Carlos Greene. Santamaría dice que recibió el texto de manos del propio Greene, aunque, al parecer, fue dictado por el general y escrito en 1916 por un periodista de la ciudad de México.

Se centra en la actuación de Greene durante la revolución constitucionalista y hace un relato detallado de algunos combates en los que participó.

Otro de los textos interesantes que reproduce Santamaría, es una memoria de Alberto Correa (1899) sobre la explotación y exportación de maderas en la República.

CONDUMEX 070.72 .62

SAN

A. No. 3120

BM

079.7263

SAN.d
Santamaria, Francisco J., Datos materiales y apuntes para la historia del periodismo en Tabasco (18251935), 2a. ed., México, Consejo Editorial del Gobierno del Estado de Tabasco, 1979, 314 p.

El autor rescató una compilación inédita sobre el movimiento periodístico en Tabasco, recogida en 1892 por Felipe J. Serra y Andrés Sánchez Abalos.

Santamaría escribió, anotó y aumentó dicho trabajo con el objetivo de informar acerca de las publicaciones de interés desde 1825 (cuando se introdujo la primera imprenta y "el primer periódico que viera la luz pública: El Argos") hasta 1935, cuando aparece Tabasco Nuevo, al final del régimen garridista.

Esta obra de difusión hemerográfica merece nuestra atención, ya que menciona y reseña muchos títulos que se han perdido y de cuya existencia tenemos noticias gracias a ella.

BIM

s.c.

Tabasco Económico. Consideraciones en torno al ferrocarril central tabasqueño (1905-1906), México,

basco, 1979, $62 \mathrm{p}$. Consejo Editorial del Gobierno del Estado de Ta-

Esta serie de artículos, sin autor, insertados en la revista semanal $E l$ Progreso de San Juan Bautista durante 1905, fueron escritos para justificar la necesidad de mejorar las vías de comunicación "que mantienen a Tabasco a la zaga del progreso nacional".

La propuesta fundamental de los artículos es la inversión gubernamental y privada en vias férreas para no dejar morir la agricultura que 
en Tabasco es pródiga y no ha alcanzado la prosperidad debida por carecer de vías de comunicación. Hace énfasis en que los adelantos materiales harán efectivo un mayor crecimiento económico.

Los juicios que emite están sustentados en una minuciosa descripción de las deplorables condiciones en que se hallaban las comunicaciones fluviales, los caminos y los puertos, para llegar a la conclusión de que la construcción del ferrocarril central tabasqueño resulta vital para establecer el enlace entre los principales centros agrícolas.

BNAL

972.62.863

Taracena, Alfonso, Los abrasados, novela tropical, TAR.a México, Ed. Botas, 1937, 164 p.

Novela ambientada en la época de Tomás Garrido

Canabal, a quien Taracena no menciona nunca por su nombre sino por el de "líder máximo". En los primeros capítulos se hace referencia a la Revolución en el estado, en forma breve.

La figura principal es Garrido Canabal: cómo comenzó a escalar posiciones en la administración estatal hasta convertirse en gobernador. Hace hincapié en las medidas que fue tomando: ley seca, anticlericalismo, criaderos de ganado, sábados rojos, asesinato de sus opositores y despojo de tierras a sus enemigos. La obra concluye con la caída del lider y la muerte del personaje que guía la novela.

CONDUMEX

910.972 .62

TAR.

Taracena Padrón, Rosendo, Compendio geográfico e histórico del estado de Tabasco (obra adaptable a las escuelas primarias), México, s.e., 1957, 159 p., maps, ils.

Esta sintesis de la historia de Tabasco, apoyada en una buena bibliografía básica, se divide en 4 partes que comprenden un indice geográfico y otro histórico. Este abarca desde la época de la conquista hasta el año de 1955. Cierra con un apéndice biográfico de algunos personajes importantes en la vida del estado.

El libro está escrito para ser utilizado por los maestros rurales, y dedicado a la niñez tabasqueña.

BIM

s.c.

Taracena Padrón, Rosendo, La Educación Pública en

Tabasco, México, Consejo Editorial del Gobierno del

TMRM Estado de Tabasco, 1980, 89 p. (Serie Historia, 26)

Esta nueva edición de la obra, escrita por primera vez en 1954, trae una "nota de información sobre el autor" de Manuel González Calzada en la cual presenta pobremente a Taracena, quien fue una figura de gran relieve en el campo educativo.

El libro en si consta de un pequeño preámbulo y 5 capítulos, además de un apéndice sobre la Dirección de Educación Federal y las obras consultadas.

Taracena explica que se dedicará "única y exclusivamente a rebuscar entre el polvo del olvido y la obscuridad de los tiempos pretéritos el proceso evolutivo que haya podido tener la educación pública en Tabasco desde la época precortesiana hasta los días presentes, pero no para que estos documentos se vean por mera curiosidad o se traten como la muda contemplación de un osario extraído de las tumbas del pasado, sino que, por medio de una atenta observación sobre la base estructural de la cultura de nuestros progenitores, se obtenga la consecuencia lógica que precise y defina el concepto claro de nuestra verdadera historia educacional". 
Los capitulos del libro se refieren a la época precortesiana, colonial, independiente, porfiriana y actual; la última parte finaliza con el discurso del gobernador del estado en 1954, año en que se celebró el 75 aniversario de la fundación del Instituto Juárez.

BIM

973.63

TAR.h

Taracena, Alfonso, Historia de la Revolución en Tabasco, México, Consejo Editorial del Gobierno del Estado de Tabasco, 1981, 2 vols.

Taracena vivió muchos de los hechos que narra y que le sirven de base para escribir una obra en la que la literatura, la crónica y la historia se mezclan. Es un libro disparejo; el autor, cuando lo considera necesario, se desvía de lo que está relatando para introducir en el texto otro asunto, que en ocasiones sólo sirve para perder la secuencia.

La obra se encuentra llena de comentarios irónicos y dolidos, atacando a otros autores que de un modo u otro se han basado en Taracena y no lo han citado como corresponde. Sin embargo, el texto es importante ya que utiliza fuentes de primera mano, testimonios y hemerografía. El rigor científico es escaso. El primer volumen va desde los comienzos de siglo hasta 1924 aproximadamente. El segundo llega a 1981 y cae más en la crónica.

BNAL

972.62072

ALE.a.

\section{BIM}

972.63

TOR.a.
Torre, León Alejo, Apuntes históricos de Tabasco o sea ojeada sobre el periodo constitucional de la administración de Dn. Victorio V. Dueñas; México, Consejo Editorial del Gobierno del Estado de Tabasco, $1979,110 \mathrm{p}$.

Este opúsculo, aunque escrito en 1862, no se publicó hasta 1931 .

El autor escribe con el objeto de contribuir al conocimiento de la historia de su estado, ya que, según él, adolece de testimonios para los sucesos importantes. La mayoría de los protagonistas en posibilidades de transmitir sus acciones por escrito, se han negado a dejar constancia, por miedo a represalias. Por ello, Alejo Torre se muestra consciente de la dificultad que entraña el relato de los acontecimientos en los que ha sido partícipe.

Estos Apuntes son importantes para comprender el periodo que va de 1857 a 1860 , en el cual las particularidades regionales se ven reflejadas en el enfrentamiento de posiciones dentro del bando liberal, durante la guerra de Reforma.

Si bien intenta presentar con objetividad los hechos, el autor no escapa de dar su opinión y de tomar partido.

Al final del texto, se transcriben una serie de documentos que sirven para aclarar asuntos tratados en la narración.

BIM

s.c.

Tostado Gutiérrez, Marcela, El Tabasco porfiriano,

e Historia)$$
\text { Villaher }
$$
1985, 179 p. (Colección Arqueología, Antropología

Primer estudio sobre la época que va de 1876 a 1910 , haciendo hincapié en los fenómenos de la vida económica del estado, analizándolos y tratándolos junto al desarrollo social y politico. La autora hace una aclaración que creemos es válida para una buena parte del texto: "El 
estudio de la tenencia de la tierra durante el periodo 1890-1917 conlleva, por principio, un margen de error considerable debido, por un lado, a la arbitrariedad en cuanto a los criterios de clasificación, levantamiento y sistematización de los datos en las fuentes primarias $\mathrm{y}$, por otro, el manejo estadístico - riesgoso las más de las veces- que de los mismos datos hacen los autores contemporáneos. Añadiremos que nuestra interpretación, basada en el análisis de ambos, constituye una tercera posibilidad de desviación".

El libro cuenta con 31 cuadros y 7 gráficas, elaborados sobre datos obtenidos del Periódico Oficial del Estado de Tabasco, informes de gobierno, censos, etc.

Se inicia con una introducción que presenta el marco histórico; le sigue un capitulo sobre "Economía" que "refiere las particularidades económicas de la formación social tabasqueña"; otro, llamado "Estructura social" y el tercero y último "El poder y el gobierno" presenta las estructuras de poder y los cambios en la política local. Hay un apartado de conclusiones; se añade la bibliografía utilizada así como los archivos; como otra de las fuentes, se mencionan entrevistas de historia oral.

INAH

LBS

PQ7244

C8

No. 271

Varela Antillón, Roque, Monografia del estado de Tabasco, México, Cuadernos de Lectura Popular, 1970, 112 p. (Serie: Monografias de México)

Constituido por 61 apartados breves, tablas comparativas y conclusiones, presenta datos oficiales $y$ esquemáticos sobre politica, economia, educación, sociedad, geografía, cultura e historia. En esta última parte no hay aparato crítico ni interpretación; la visión es superficial y carece de mayor utilidad. Abarca desde el prehispánico hasta la Revolución y dedica más atención al México antiguo y colonial. Para el resto de la información, toma datos de la Secretaría de Marina y de los censos generales de población de 1960 y 1970.

Al final se refiere al exgobernador Francisco Trujillo y sus colaboradores; menciona a Mario Trujillo, sobrino del anterior, en ese momento candidato a la gubernatura por el PRI. Trata temas tan diversos y fuera de contexto como es el apartado que se refiere a los insectos.

BIM

972.63

WES.t

COPLADET

s.c.

West, Robert C., et al., Las Tierras Bajas de Tabasco en el Sureste de México, Trad. Patricio Escalante Guerra, Villahermosa, Gobierno del Estado de Tabasco, 1976, $200 \mathrm{p}$.

Esta monografía, estudio científico-geográfico, atiende las características físicas y culturales con relaciones históricas de la "sección costera, húmeda y

tropical del sureste de México, que bordea la parte extrema meridional dẹl Golfo, e integra los llanos costeros aluviales más grandes de la República $(. .$.$) incluye casi todo el estado de Tabasco, porción norte de$ Chiapas y occidente de Campeche" (Tierras Bajas).

La Universidad Estatal de Luisiana patrocinó los trabajos de campo e investigación en archivos y bibliotecas, hechos entre 1962 y 1963 por los norteamericanos Robert C. West, David Barlow, Bruce Thom y Norbert Psuty. Intentan demostrar que después de cuatro siglos de descenso económico y demográfico, estos aspectos se han recuperado recientemente, y son comparables a los que existieron en el prehispánico. 
El libro cuenta con datos históricos valiosos, desde tiempos antiguos hasta 1960. Contiene indices de láminas y tablas, introducción, ocho capitulos (con notas), tres apéndices y referencias a lo utilizado. El manejo de fuentes primarias y secundarias, de mapas topográficos y fotografías aéreas y terrestres; de materiales de archivos y bibliotecas mexicanos, norteamericanos y españoles, constituyen un rico aparato crítico.

\section{BIBLIOTECAS CONSULTADAS}

B1M Biblioteca Instituto Mora

BM (FB) Biblioteca México (Fondo Basave)

BM Biblioteca México

BNAL Biblioteca Nacional

CICOM Centro de Investigaciones de las Culturas Olmeca y Maya (Tabasco)

CONDUMEX Biblioteca Centro de Estudios de Historia de México

COPLADET Comité de Planeación para el desarrollo del Estado de Tabasco

HNAL Hemeroteca Nacional

INAH Biblioteca del Instituto Nacional de Antropología e Historia.

TJM Biblioteca José Martí de la Universidad Autónoma Juárez de Tabasco

TMRM Biblioteca Manuel R. Mora (Tabasco) 